\title{
COVID-19 pandemic: Understanding the emergence, pathogenesis and containment (Review)
}

\author{
MOHAMMAD K. PARVEZ ${ }^{1}$, RAJESH M. JAGIRDAR ${ }^{2,3}$, RAM S. PURTY ${ }^{4}$, SURESH K.S. VENKATA ${ }^{5}$, \\ VISHAL AGRAWAL $^{6}$, JITENDRA KUMAR $^{7}$ and NEERAJ TIWARI ${ }^{8}$
}

\author{
${ }^{1}$ Department of Pharmacognosy, King Saud University College of Pharmacy, Riyadh 11451, \\ Kingdom of Saudi Arabia; ${ }^{2}$ Department of Physiology, Faculty of Medicine, University of Thessaly, Larissa 41110; \\ ${ }^{3}$ Division of Nephrology and Hypertension, Medical School, Aristotle University of Thessaloniki, \\ Thessaloniki 541 24, Greece; ${ }^{4}$ University School of Biotechnology, Guru Gobind Singh Indraprastha University, Dwarka, \\ New Delhi 110078; ${ }^{5}$ Navipointgenomics India Private Limited, Mysore, Karnataka 570006; ${ }^{6}$ Department of Biochemistry, \\ Panjab University, Chandigarh 160014, India; ${ }^{7}$ Department of Biochemistry, Faculty of Medicine and Dentistry, \\ University of Alberta, Edmonton, AB T6G 2R7, Canada; ${ }^{8}$ Pfizer Clinical Research Unit, New Haven, CT 06511, USA
}

Received May 5, 2020; Accepted July 7, 2020

DOI: $10.3892 /$ wasj.2020.59

\begin{abstract}
The ongoing crisis of the novel SARS-CoV-2 disease (COVID-19) has forced several countries to resort to extreme public health measures at a level never encountered in the past century. Originating in Wuhan, China, this is the third highly pathogenic coronavirus $(\mathrm{CoV})$ following SARS-CoV-1 and MERS-CoV. As of June 20, 2020, >8.6 million of the world population were infected with SARS-COV-2, and almost 0.46 million individuals have succumbed to the disease. After 6 months of the outbreak, the understanding of the pathobiology and epidemiology of COVID-19, as well as clinical management strategies have increased substantially. The phylogenetic analysis of SARS-CoV-2, exhibiting close similarity ( 96\%) with bat SARS-like CoV has indicated its zoonosis in bats. The human-to-human transmission of COVID-19 has been confirmed through multiple modes, such as nasal droplets, oral mucus, aerosols and fomites. SARS-CoV-2 has an incubation period of 2-14 days with symptoms of fever, cough and breathlessness, which may manifest from mild pneumonia to severe illness and death. Currently, RT-PCR and antibody-based test kits are being used for the identification of infected individuals. Owing to the lack of specific available treatments, several repurposed drugs and new vaccine candidates are currently undergoing phase I/II clinical trials and are expected to be available to the public as soon as possible. Nonetheless, it is imperative for world bodies to unite in combating this
\end{abstract}

Correspondence to: Dr Mohammad K. Parvez, Department of Pharmacognosy, King Saud University College of Pharmacy, Riyadh 11451, Kingdom of Saudi Arabia

E-mail: khalid_parvez@yahoo.com; mohkhalid@ksu.edu.sa

Key words: coronavirus, COVID-19, SARS-CoV-2, zoonosis, pandemics, remdesivir pandemic by developing cost-effective kits and therapeutics, and making them available to resource-poor countries.

\section{Contents}

1. Introduction

2. Infection and epidemiology

3. Virus biology

4. Clinical presentation and immuno-pathobiology

5. Non-respiratory manifestations

6 . Source of origin

7. Modes of transmission

8. Socio-environmental drivers of the outbreak

9. Human adaptation

10. Diagnosis and treatment options

11. Vaccine and preventive measures

12. Mathematical model of assessing viral evolution and epidemics

13. Risk factors

14. Conclusion and future perspectives

\section{Introduction}

The current COVID-19 pandemic caused by severe acute respiratory syndrome coronavirus-2 (SARS-CoV-2) has markedly affected the world population (1). Epidemiology has encountered several pathogenic viral outbreaks in the past (2), and of these, the 1918 'Spanish Flu' or 'La Gripe Espanola' pandemic had exerted the worst toll on human health and the global economy $(3,4)$. Viruses are complex 'biocapsules' with genomic material (DNA or RNA), wrapped in a protein coat. They are inherently obligate intracellular parasites, and must invade live cells and hijack host machinery to complete their life cycle. According to the International Committee on Taxonomy of Viruses (ICTV), all known viruses are classified under 3 orders, 56 families, 9 subfamilies and 233 genera of 
$>1,550$ species (5). Current knowledge is limited when it comes to their natural 'reservoirs' among farm animals, pets, poultry and wildlife, and subsequent zoonosis to humans. Recent examples of pathogenic virus outbreaks, including influenza virus, Hendra virus, Ebola virus, Nipah virus, Zika virus, hantavirus and coronavirus, have been linked to zoonosis (3).

The newly identified SARS-CoV-2 originated in December, 2019 in Wuhan, China (6). It is the third highly pathogenic human coronavirus (HCoV) after the 2002-3 SARS-CoV (renamed, SARS-CoV-1) and the 2012-13 Middle-East respiratory syndrome $\mathrm{CoV}$ (MERS-CoV) outbreaks (7). Similar to MERS-CoV infection, SARS-CoV-2 has an incubation period of 2-14 days with symptoms of fever, cough and breathlessness, which may manifest from mild pneumonia to severe illness and even subsequent death $(1,7,8)$. The present 2019-20 SARS-CoV-2 pandemic closely mirrors the events in 'Contagion', a 2011 Hollywood movie about a deadly virus outbreak in the USA, which originated in Hong Kong, and resulted in social disorder and chaos in healthcare system until a vaccine was introduced. Currently, several repurposed drugs, such as hydroxychloroquine, remdesivir, azithromycin and dexamethasone, as well as some vaccine candidates, are undergoing phase I/II clinical trials. The present review article presents a sincere effort towards updating the current understanding of the emergence, pandemic status, pathogenesis and containment measures of COVID-19.

\section{Infection and epidemiology}

The impact of a pandemic depends upon the number of individuals infected, and countries affected by its transmissibility, severity and spectrum of clinical manifestations. To date, SARS-CoV-2 has affected $>200$ countries and territories (Fig. 1). As of June 20, 2020, the global confirmed cases of COVID-19 have spiked to $>8.6$ million, including 460,080 deaths. This includes 285,648 from Africa with most cases noted in South Africa (87,715); 1,788,752 from Asia with most cases in India $(395,048)$, Iran $(200,262)$ and China $(80,012) ; 4,282,308$ from the Americas, with most cases in the USA $(1,133,069)$ and Brazil (1,032 913); 2,268,266 cases from Europe, with most cases in Russia (569,063), UK (301, 815), Spain $(245,575)$ and Italy $(238,011)$; and 8,905 cases from Oceania, with most cases in Australia (7,409) (9).

After six months of the first emergence of SARS-CoV-2 in December, 2019 and its rapid global spread in the northern and southern hemispheres, seasonal variation has not significantly affected its transmissibility. SARS-CoV-2 has a high basic reproductive number (R0), ranging between 2.0 to 2.5 days (9). The R0 measures the average number of infections that can result from one infected individual in a susceptible population (10). R0 has been, however, estimated with varying results and interpretations. The current estimate of the mortality rate for COVID-19 is $3.4 \%$, which is significantly higher than that of seasonal flu $(0.02 \%)$, but lower than that of SARS-COV-1 (9.6\%) and MERS-CoV (34\%). Affected individuals, mostly males in the elderly population or those with underlying medical conditions, such as hypertension, diabetes, or chronic respiratory, renal and hepatic issues, have exhibited a higher mortality rate (11).

\section{Virus biology}

SARS-CoV-2 is classified together with SARS-CoV-1, MERS-CoV, HCoV-OC43 and HCoV-HKU1 within the genus Betacoronavirus of the Coronaviridae family, and has a positive sense, single-strand RNA $(\sim 29.9 \mathrm{~kb})$ genome $(11,12)$. The viral RNA is 5'capped and consists of 13 active open reading frames (ORFs) that encode a total of 27 proteins, i.e., 16 non-structural, 4 structural and 7 accessory proteins (13). However, in a recent sequence analysis of Betacoronavirus, SARS-CoV-2 has shown that nonsense mutations introduced 6-stop codons in the accessory coding region, which could fail to translate ' $3 b$ ' (Padhan and Parvez, unpublished data). This observation has consolidated the number of accessory proteins to 6 instead of 7, and the total proteins to 26 in SARS-CoV-2.

The first SARS-CoV-2 RNA sequence (GenBank accession no. MN908947) was reported using metagenomic sequencing technologies (14). Phylogenetic analysis of the viral genome has indicated its close similarity ( $96 \%$ identity) with two bat-SARS-like coronaviruses (SL-CoV) viz., bat-SL-CoVZC45 and bat-SL-CoVZXC21, but its distinction from SARS-CoV-1 ( 79\% similarity) and MERS-CoV (15). SARS-CoV-2 has 4 structural proteins: Crown-like spike (S), envelope (E), membrane (M) and nucleocapsid (N) (Fig. 2A). The ' $\mathrm{S}$ ' protein is a type I transmembrane glycoprotein that shares $\sim 76 \%$ sequence identity with that of SARS-CoV-1 and $\sim 80 \%$ identity with bat-SL-CoV (16-18). 'S' has two structural subunits ( $\mathrm{S} 1$ and $\mathrm{S} 2$ ), of which the 'S1' subunit contains the human cell-receptor angiotensin-converting enzyme-2 (ACE2) receptor-binding domain (RBD). The 'S2' subunit contains the structural elements required for membrane fusion. While the amino acid sequence of the 'S1' subunit is highly variable ( $\sim 70 \%$ sequence identity with bat-SL-CoV and SARS-CoV-1), 'S2' sequence is highly conserved and shares $~ 99 \%$ identity with both bat-SL-CoV and SARS-CoV-1 $(17,19)$. Notably, of 6 six amino acid residues of RBD, 5 differ between SARS-CoV-2 and SARS-CoV-1, suggesting the strong binding of the SARS-CoV-2 spikes with ACE2 receptor and high infectivity $(20,21)$. The ' $M$ ' is a trans-membrane glycoprotein, crucial for virion's fusion with the host cell membrane, whereas the ' $\mathrm{E}$ ' protein is necessary for the assembly and morphogenesis of nascent virions (22). In the case of SARS-CoV-1 infection, the ' $\mathrm{N}$ ' protein is highly antigenic, which triggers the production of SARS-CoV antibodies in approximately $89 \%$ of infected patients and is used as a serological marker (23).

The SARS-CoV-2 non-structural replicase proteins, ppla (nsp1-nsp11) and pp1b (nsp12-nsp16), are involved in viral RNA transcription and replication (Fig. 2B), as well as in modulating host-innate immunity. SARS-CoV-2 varies in its conserved aggregation motif of the ' $3 \mathrm{a}$ ' accessory protein with SARS-CoV-1, as well as civet-SL-CoV (paguma-SARS-CoV) and bat-SL-CoV (YNLF_31C and NLF_34C) (24).

\section{Clinical presentation and immuno-pathobiology}

The incubation period for SARS-CoV-2 varies from 2-14 days with a mean incubation period of 6.4 days. This is higher than that of seasonal flu (2 days), swine flu (1-4 days), MERS-CoV (2-14 days) and SARS-CoV-1 (2-7 days) (25). Almost $80 \%$ of infections with SARS-CoV-2 remain asymptomatic or 


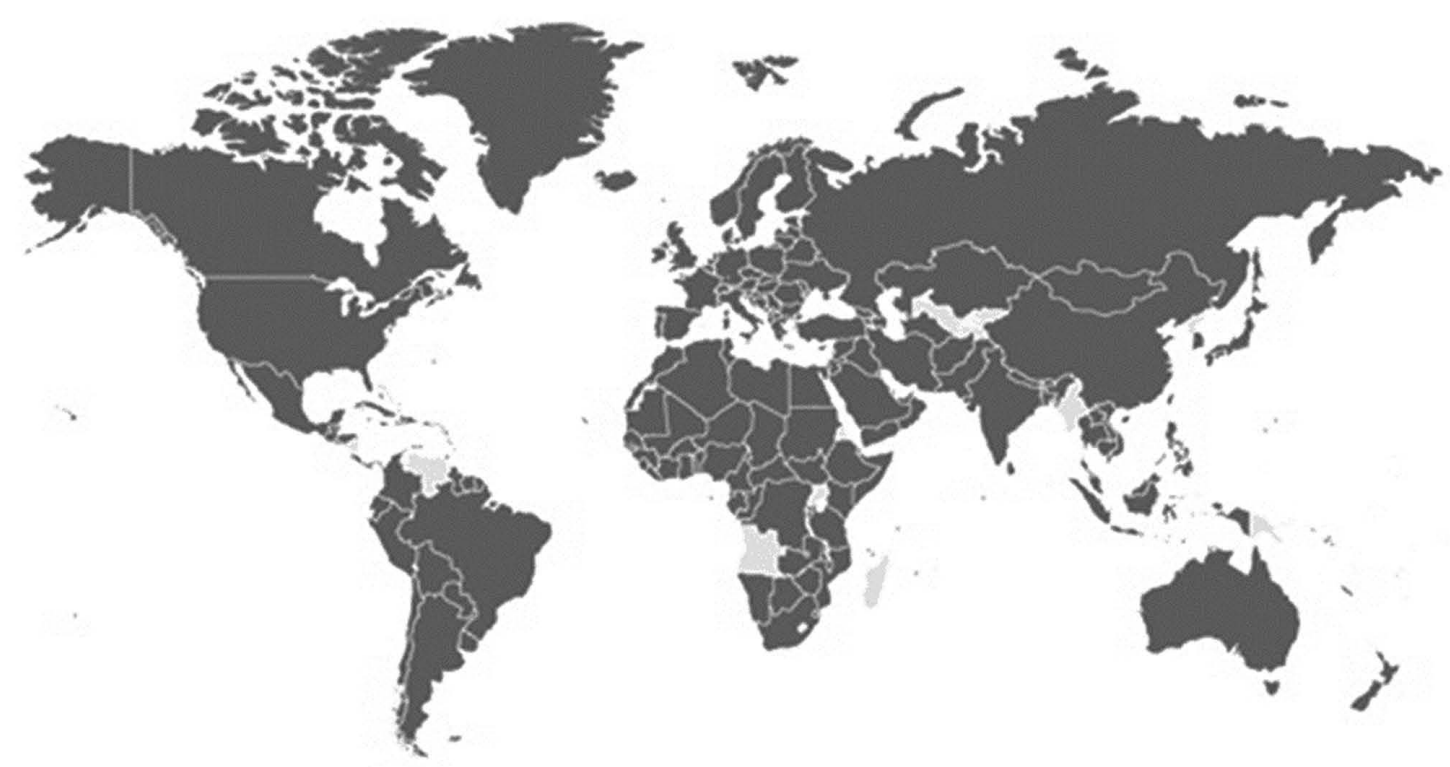

Figure 1. World map illustrating the current epidemiology of COVID-19 (shown in dark gray; https://www.cdc.gov/coronavirus/2019-ncov/casesupdates/world-map.html).
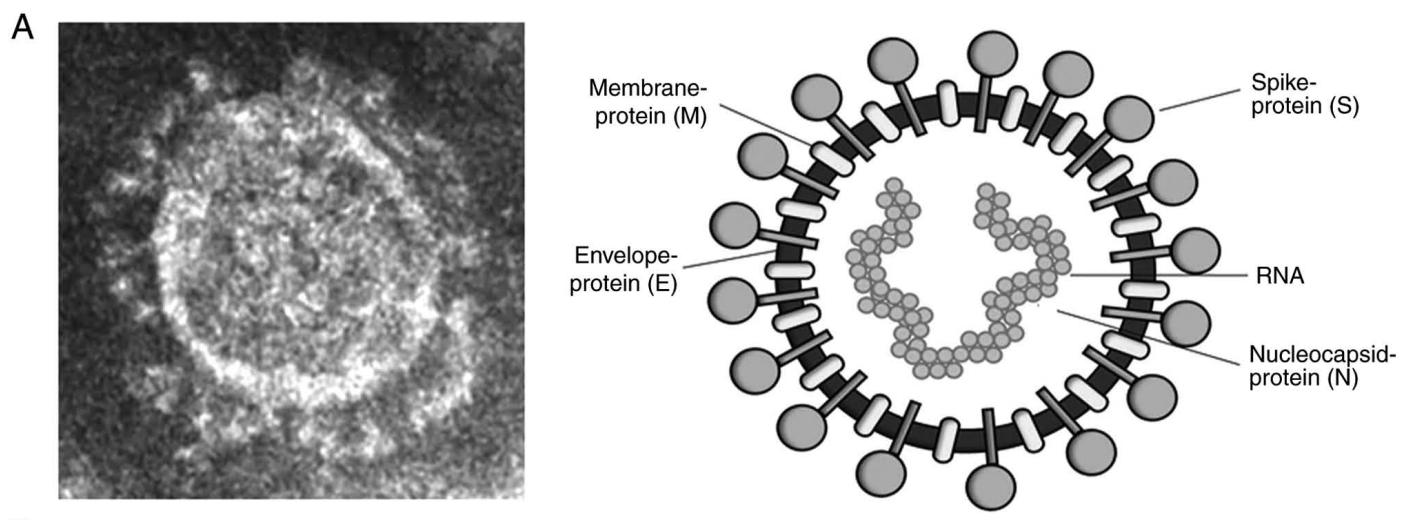

B
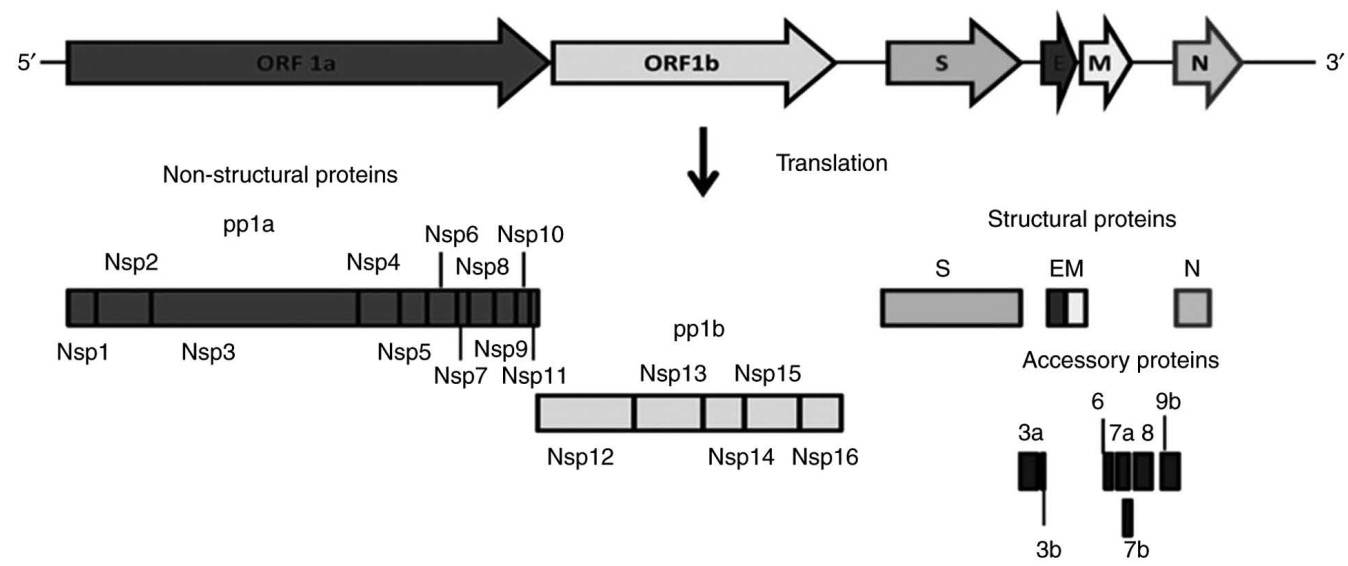

Figure 2. Structural and molecular organization of SARS-CoV-2. (A) Electron micrograph of SARS-CoV-2 (left panel; adapted from https://www.uva. $\mathrm{nl} /$ en/current/coronavirus/coronavirus.html) and a cartoon representation of its structure (right panel). (B) Schematic diagram of viral genome organization showing open reading frames and encoded non-structural (ppla and pplb) and structural (spike, S; envelope, E; membrane, M; and nucleocapsid, N) and accessory proteins.

exhibit very mild flu-like symptoms and can recover at home. However, the severe cases (15\%) exhibit high fever, pneumonia and breathlessness, thus requiring hospitalization. In addition, $5 \%$ of cases develop respiratory failure, septic shock and multi-organ failure (Fig. 3). Patients infected with COVID-19 with severe pneumonia present ground-glass opacity and lung consolidation features. In $>70 \%$ of COVID-19 suspected cases, the disease was apparent in all the 5 lobes of the lung (26). In 


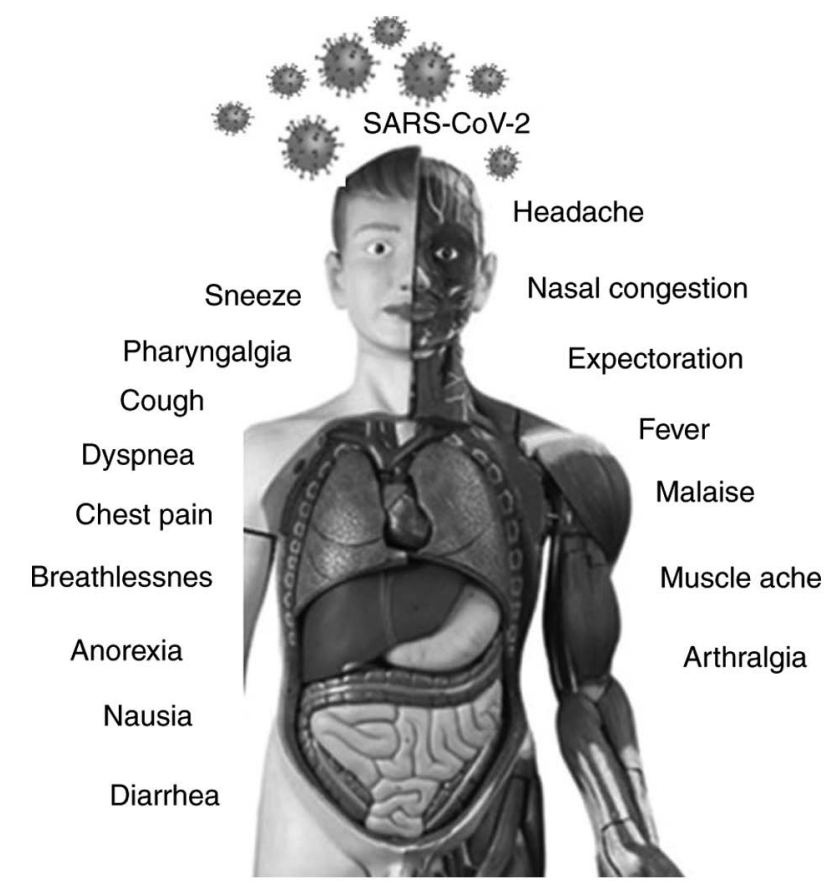

Figure 3. COVID-19 infection and associated signs and symptoms in humans.

addition to the ground-glass opacity, lung consolidation has also been reported with peripheral $(41 \%)$, lower zone $(50 \%)$ and bilateral involvements (50\%) (27).

Human betacoronaviruses exhibit high species-specificity; however, subtle genetic changes can significantly alter their tissue-tropism, host-barrier and pathogenicity, as observed with SARS-CoV-1 and MERS-CoV. The bat-SL-CoVs are known to use their ' $S$ ' protein (RBD) to bind to civet and horseshoe bat ACE2 receptors (28). Similarly, the SARS-CoV-2 ' $S$ ' protein also binds to the ACE2 of the airway epithelium and alveolar type-2 pneumocytes, pulmonary cells that synthesize pulmonary surfactant (29), where the ' $M$ ' fusion protein facilitates cell entry (21).

When SARS-CoV-2-contaminated droplets are inhaled, the virus first becomes attached to the inner linings of the throat and larynx, and remains there for few days. Though generally mild, SARS-CoV-2 can cause severe symptoms when it travels down the respiratory tract and infects the lungs, which are even more abundant in ACE2. As a result, a number of the pulmonary cells are damaged. In more severe cases, the immune system of the infected individual goes into 'overdrive', attracting immune cells to the lungs to attack the virus, resulting in the inflammation of the lungs. In most severe cases, more immune cells rush in, and the inflammation becomes more severe; this process is known as a 'cytokine-storm' and may lead to death. Ample studies have demonstrated that patients with severe pneumonia may rapidly progress to acute respiratory distress syndrome (ARDS), septic shock or multiple organ failure and death (11). As ACE2 is abundantly present on ciliated cells of the airway epithelium and lung alveolar type- 2 cells, ARDS progression, and extensive lung damage in patients infected with COVID-19 are inevitable (30). However, the mechanism through which SARS-CoV-2 is able to inhibit or evade host-innate immune responses to initiate severe pathogenesis remain unclear. Given that SARS-CoV-2 has similar clinical manifestations as SARS-CoV-1 and MERS-CoV, it may have a common mechanism of etiology (8). Furthermore, certain individuals have genetic variants of ACE2 that are slightly more vulnerable to SARS-CoV-2 than those of the majority in the population. In addition, individuals with diabetes or hypertension have significantly increased levels of ACE2, which renders them more susceptible to the virus (31).

In general, the type-I interferon (IFN)-induced expression of IFN-stimulated genes (ISGs) significantly inhibits viral replication when challenged by infection. Given this cellular antiviral activity, SARS-CoV-2-encoded non-structural and accessory proteins are suggested to modulate the induction of IFN and cytokines, and evade the ISG response (32). In addition, the host-immune responses through inflammatory and cytotoxic lymphocyte (CTL) activities are critical to inhibiting viral replication and dissemination. Therefore, the immune overdrive, together with the cytolytic effects of the virus, results in disease severity. In addition, certain respiratory viruses, including $\mathrm{HCoV}$, also induce an increase in the levels of liver function biomarkers, very likely related to liver inflammation or damage as a result of IL-6-triggered CTL and Kupffer cell activities (33). Similarly, in some patients with COVID-19, cases of hepatitis have also been observed (34).

\section{Non-respiratory manifestations}

A good proportion of COVID-19 patients have exhibited evidence of gastrointestinal symptoms in response to SARS-CoV-2 infection (34). In a recent study from Wuhan, approximately $10 \%$ of hospitalized patients with COVID-19 presented with diarrhea, nausea, vomiting and abdominal pain within 1-2 days prior to the onset of COVID-19 symptoms, such as fever and dyspnea (34). Although liver function indices are a noticeable feature of COVID-19 pathology, they are currently not considered a 'prominent feature' (35). Nonetheless, COVID-19 has been linked to mild to moderate liver injury, as revealed by elevated levels of serum aminotransferases, bilirubin, hypoproteinemia and prothrombin time prolongation, supported by liver histopathology $(33,36-38)$. Single-cell RNA sequencing data from 2 distinct cohorts of patients with COVID-19 have demonstrated the higher expression of ACE2 in cholangiocytes than in hepatocytes, indicating that SARS-CoV-2 may directly affect intrahepatic bile ducts (39). Taken together, SARS-CoV-2 is proposed to induce viral hepatitis, while inducing a dysregulated innate immune response. In general, patients with COVID-19 presenting with digestive issues before respiratory problems have a higher risk of mortality compared to those without digestive symptoms.

Cardiac comorbidity has also been reported among a proportion of patients with COVID-19. Underlying cardiac disease, arrhythmia and hypertension have been observed twice as often among critical cases compared to non-critical patients $(36,40,41)$. Two pathological indicators of cardiac injury, i.e., elevations in myoglobin (15-17\%) and cardiotroponin $(8-12 \%)$ levels, have been reported in patients with COVID-19 (42). COVID-19 disease severity was also demonstrated to be positively associated with significantly higher values of troponin and creatine kinase compared to those of less severe cases. Moreover, a previous meta-regression analysis revealed an association of the disease severity with 
hypertension (43). These clinical observations highlight the importance of the correct and timely diagnosis and treatment of non-respiratory symptoms along with pneumonia in order to reduce the case fatality rate.

\section{Source of origin}

The risk of infection is high when viruses transmit into humans from non-human primates than those from bovine, porcine, feline, or rodent mammals. For instance, SARS-CoV-1 has been previously detected in masked-palm or gem-faced civet cats sold at Chinese wildlife/wet markets $(44,45)$. The first source of origin, high transmission and mechanisms of the severity of SARS-CoV-2 in humans are hitherto not clearly established. However, the virus certainly originated in bats and transferred to other mammals, such as the pangolin, and subsequently to its handler or 'patient zero' at the Wuhan market (Fig. 4). Nonetheless, a recent data analysis of multiple SARS-CoV genomes suggested the natural evolution of SARS-CoV-2 (46). Previously, the global outbreaks of SARS-CoV-1 and MERS-CoV were linked to zoonosis due to their close genetic homology to bat-SL-CoV, but not to any other known HCoV (47). Bats are known to harbor the most enormous diversity of $\mathrm{CoV}$, which varies from species-to-species and region-to-region $(45,46,48)$. Camels are also identified as a potential source of MERS-CoV transmission to humans (49). Notably, while zoonosis (anthropozoonosis) of COVID-19 is established, a few cases of reverse-zoonosis (zooanthroponosis) in pets and zoo animals are currently being reported (50).

\section{Modes of transmission}

A number of viruses that affect the respiratory system, such as the influenza virus, respiratory syncytial virus, MERS-CoV and SARS-CoV-1, are mainly transmitted when an infected individual expels virus-loaded water droplets by coughing or sneezing. The human-to-human direct transmission of COVID-19 has been confirmed through multiple modes, such as nasal droplets, aerosols and oral mucus (8). Recently, anal swabs were shown to contain SARS-CoV-2 RNA in high amounts, compared to oral swabs, suggesting the possible fecal-oral transmission of SARS-CoV-2 (51). Furthermore, in pediatric cases of COVID-19, rectal swabs persistently tested RNA-positive, even though nasopharyngeal tests were negative (52). In other studies from China, stool specimens of patients were found positive, even after viral clearance, presenting evidence of SARS-CoV-2 shedding in stool (53-55). Moreover, cell-culture produced SARS-CoV-2 has been shown to survive in aerosols for $3 \mathrm{~h}$, on copper for $4 \mathrm{~h}$, on cardboard for $24 \mathrm{~h}$, and on plastic and stainless steel surfaces for up to 2-3 days (56). These results provide vital information about the environmental stability of SARS-CoV-2 and suggest potential sources of viral contaminations.

\section{Socio-environmental drivers of the outbreak}

Pathogenic viruses introduced into new regions often cause highly contagious and devastating pandemics, such as COVID-19. Recurrent outbreaks of novel human viruses suggest the ability the virus to rapidly adapt compared to the other pathogenic microbes. There exists a pool of unknown viruses that are likely to evolve more rapidly over time, of which some tend to disappear in the course of evolution, while others continue to emerge aggressively (3). Generally, new viruses appear when humans are exposed for the first time, to an evolved virus from other animal hosts. Such viruses may either become pathogenic in new non-human hosts or may further evolve into more aggressive strains in humans. Therefore, humans are merely 'incidental' or 'spillover' hosts (2).

Furthermore, to understand the evolution of novel viruses is to know the intricate 'host-pathogen-environment' interplay. While the emergence of new infections, such as COVID-19 in naïve regions, is caused primarily by human movement, local emergence is driven by a combination of environmental and social/traditional changes. Notably, viral transmission rates are often higher in dense than in sparse populations, and social contacts greatly enhance the spreading of the virus. Moreover, the growing human population, global changes in geographical distribution and the introduction of anthropophilic vectors affect selective pressure on primary hosts of evolving viruses (3).

Furthermore, there is a key question for individuals residing in tropical countries, namely that of whether the warm season would eradicate SARS-CoV-2. Generally, the respiratory, flu, or pneumonia viruses, including certain $\mathrm{CoV}$ lifecycles survive in cold seasons, and gradually subside when the temperature rises. For example, the SARS-CoV-1 spread in 2003 was rapidly contained, leaving little information on the effect of seasonal variations on disease spread. Since the emergence of SARS-CoV-2 in China in December, 2019, a number of large-scale outbreaks have been observed in regions where the weather is cooler, leading to speculation that the virus would diminish with the arrival of summer. However, SARS-CoV-2 is too novel to postulate any pattern of survival as to how it will behave with the season changes. An unpublished analysis comparing the weather in COVID-19-affected 500 locations suggested a link between its spread and temperature and relative humidity; however, it was noted that temperature alone cannot account for the global variation in incidence (12). Although the emergence of SARS-CoV-2 in colder weather indicates for its plausible seasonality, the arrival of summer in several regions has not significantly affected the rate of infection.

\section{Human adaptation}

A zoonotic infection is initially poorly adapted in a new host, slowly replicated and inefficiently transmitted. Therefore, its animal-to-human and human-to-human transmission greatly depends on its evolution to a virulent strain that can well adapt to the human host. RNA viruses have a much more recent evolutionary history and 'human adaptation' for only thousands of years as compared to DNA viruses evolving and diversifying for millions of years (2). Owing to the high replication-fidelity rate of their polymerase/reverse-transcriptase enzymes $\left(\sim 10^{-4}\right.$ error/site/cycle), RNA viruses are more genetically diversified than DNA viruses. In the process of evolution and adaptation of RNA viruses, genetic mutations, re-assortment or virus-host genetic recombination may lead to the establishment of stable strains or lineages in human populations (3). 


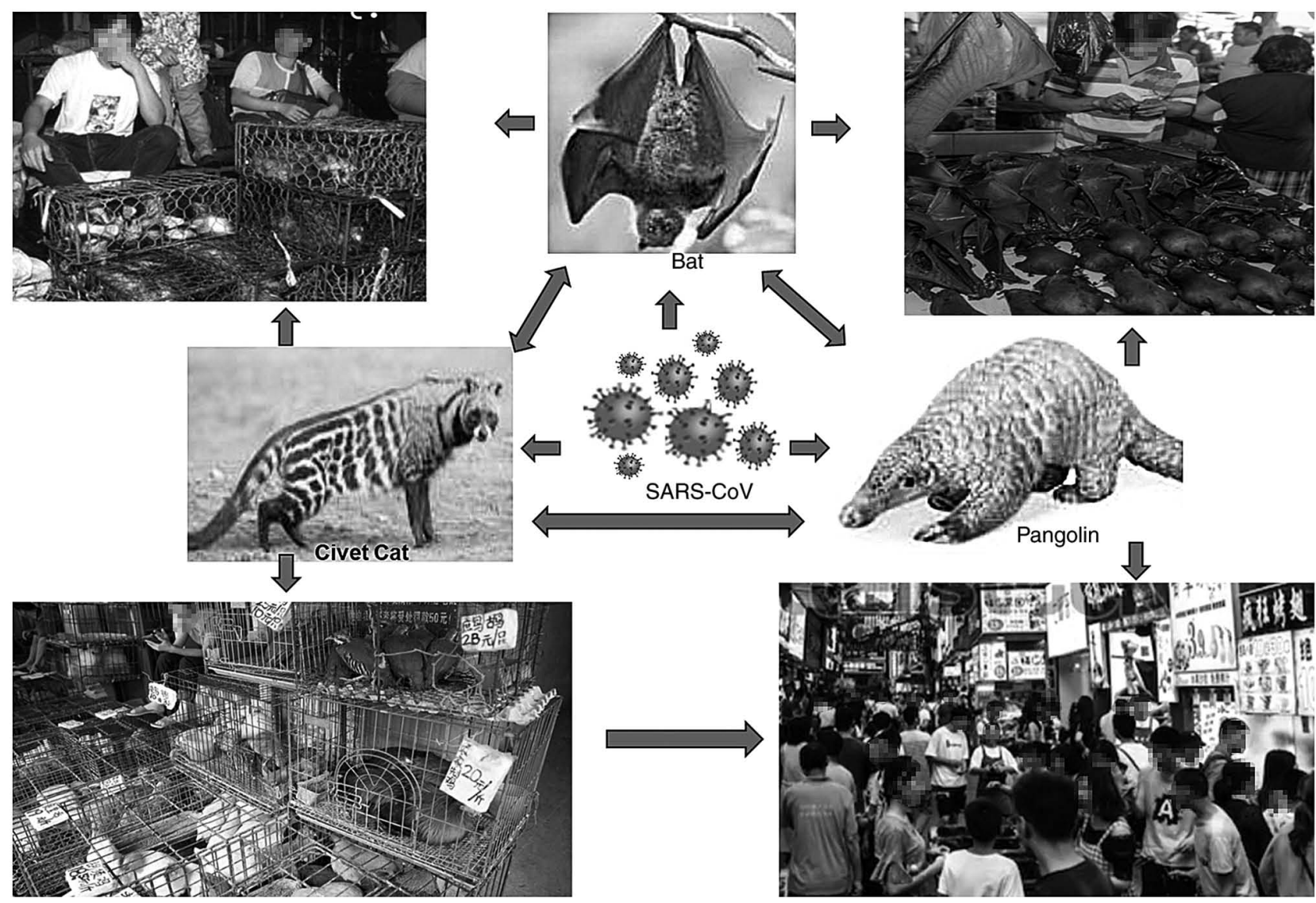

Figure 4. Coronavirus (SARS-CoV-2) zoonosis and transmission. The figure shows the most possible transmission of SARS-CoV-2 from its reservoir (bat) or intermediate hosts (civet cat and pangolin) to animal handlers and meat consumers.

Therefore, it is very much expected that human-adapted novel viruses, such as SARS-CoV-2, could circulate asymptomatically and remain undetected until they manifest in the infected population. However, only a minority of these would persist in specific populations (endemics), spreading across populations (epidemics) or globally (pandemics) in the absence of an established reservoir.

In addition, differential host factors, such as age, health, physiology, nutritional status, exposure history, concomitant infections, immuno-competence, underlying comorbidities and genetics significantly determine the susceptibility of an individual to a novel infection. As observed with COVID-19 infection, older-aged and immune-compromised individuals are the most commonly affected population, worldwide. Notably, the severity of COVID-19 in patients with chronic disease with poor immunity becomes more inevitable compared to other critically ill patients with pneumonia.

\section{Diagnosis and treatment options}

While COVID-19 is rapidly spreading along with other respiratory viruses in circulation, proper screening and sensitive diagnostic tools are required to control its further spread. A chest X-ray and CT scan are the clinical methods of non-invasive pulmonary assessment. Nasopharyngeal and oropharyngeal swabs, as well as sputum, tracheal aspirate, or bronchoalveolar lavage are the recommended specimens for viral RNA molecular (RT-PCR) testing (57). In the cases of digestive issues, the testing of rectal swabs and stool samples of patients with COVID-19 is warranted (34). Pan-coronavirus based serological or antibody test kits are now being extensively used in several countries, in order to assess the protective immunity in patients who recovered from COVID-19. Although the acquired immunity and longevity against SARS-CoV-2 remain poorly understood, these antibodies could be used as part of a broader range of care, such as plasma therapy. At this moment, the test kits that are largely produced in China, are being reported for inaccurate and unreliable results in countries, such as the UK, France and India. Currently, few laboratories outside China have also begun the production of rapid COVID-19 antibody test kits (Fig. 5, left panel).

The WHO has recommended case definitions for COVID-19 (1) that can however, vary in countries or even within a given region over time. Suspected cases of COVID-19 are those with severe acute respiratory infections requiring hospitalization, and thoroughly explaining the clinical presentation and a history of visiting China or any infected population, during the 14 days prior to symptom onset. In either case, contact with a confirmed or suspected case or working in or shared a healthcare center where patients with COVID-19 were treated. Therefore, probable cases are those for whom the COVID-19 test is inconclusive or those tested SARS-CoV-2-positive, and negative for laboratory evidence of 


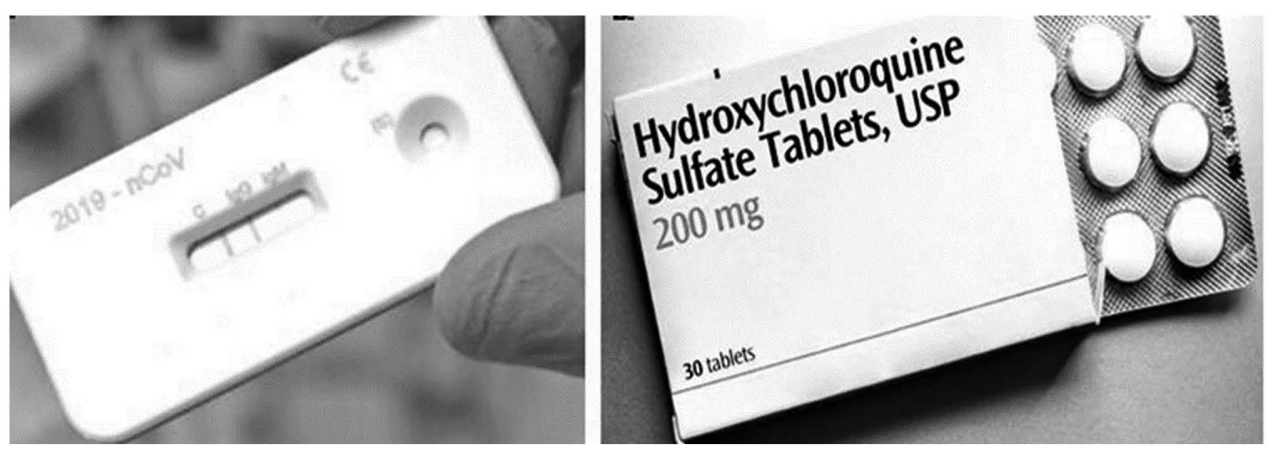

Figure 5. The COVID19 diagnostics and treatment: Examples include, antibody test strip (InfectoGnostics) (left panel) and hydroxychloroquine (Zydus Cadila) that has recently become controversial (right panel).

other respiratory viruses. As per the WHO, a positive case is one with a laboratory confirmation of SARS-CoV-2 infection, irrespective of clinical manifestations.

At present, there is no specific treatment regimen available for COVID-19. As part of the 'Solidarity Trial' for hundreds of COVID-19 treatments and interventions, the anti-malarial drug, hydroxychloroquine (Fig. 5, right panel), the anti-Ebola drug, remdesivir, the broad-spectrum antibiotic, azithromycin, including the anti-retroviral drug, lopinavir, in combination with ritonavir and IFN- $\alpha-1 \mathrm{a}$ are currently in advanced stages of clinical investigations (www.COVID19ResponseFund.org). Of these, remdesivir has recently been approved for 'emergency use' by the US Food and Drug Administration. In addition, while the anti-influenza drug, favipiravir, has completed the phase III trials in Japan and entered the US phase II investigation, it has now been approved in Russia for hospitalized patients. Thus far, there is no consensus clinical guidance available on the use, dosing or duration of treatment in patients with COVID-19 (7). There are however, safety concerns that some of these drugs may cause cardiotoxicity with prolonged use in patients with pre-existing chronic conditions, such as renal failure and hepatic disease (58-60).

Nonetheless, though a small sample size, case studies of patients with COVID-19 with liver issues suggest focusing on modulating innate-immune dysfunction besides antiviral trials (35). Recently, tocilizumab and sarilumab, IL-6 receptor antagonists, have been approved for phase II/III trials in hospitalized patients with COVID-19 with severe pneumonia (https://clinicaltrials.gov/ct2/). Moreover, several other pharmacophores and chemotherapies, such as camostat mesylate and mefloquine, are undergoing clinical investigations in some countries (61).

\section{Vaccine and preventive measures}

Developing a vaccine is the optimal preventive measure; however, it is also the most time-consuming and most complex process, which may require significant amounts of time ranging from 24-30 months. Nonetheless, rapid initiatives have been already taken, and over 8 promising vaccines candidates, notably mRNA-1273 (Moderna, Inc.), Ad5-nCoV (CanSino Biologics), ChAdOx1-nCoV-19 (The Oxford Group); INO-4800 (Inovio Pharmaceuticals Inc.), and LV-SMENP-DC (Shenzhen Geno-immune Medical Institute) are currently undergoing phase I/II trials $(62,63)$. Large scale phase III trials are, therefore, warranted to determine their optimal required dose, efficacies in elderly individuals and minimal side-effects. Additionally, it should be determined whether any additional adjuvant is required to further boost their effectiveness, before approval and licensing.

Moreover, reasonably high levels of neutralizing antibodies termed 'herd immunity' are produced in patients with COVID-19 that maybe protective against future infections. 'Plasma therapy' with significant outcomes has therefore been adopted in some countries. However, this will not last for $>2$ years, as observed with other $\mathrm{HCoV}$ infections, where even if the majority of the population do eventually become exposed, the virus is still likely to become endemic. The SARS-CoV-2 will be circulating among us for some time and may become less pathogenic or may mutate to become more lethal. In summary, COVID-19 does what past flu pandemics have done, leaving behind enough immune survivors and searching for viable targets.

In the present situation, the first and most important measure is to immediately quarantine COVID-19-positive or suspected individuals, while enforcing public health safety guidelines on social distancing, the use of sanitizers, protective masks and gloves. Given the scarcity of medical facilities, clinical equipment and the lack of treatment options, COVID-19 has forced several countries to resort to extreme public health measures, such as the lockdown of cities, suspending domestic and international travel, and sealing international borders, never before observed over the past century. A quantitative investigation on the impact of the travel ban has revealed a significant positive association between population movement and controlling the spread of COVID-19 in mainland China $(64,65)$.

\section{Mathematical model of assessing viral evolution and epidemics}

Patterns of pathogen evolution and spread are similar in the way that information or rumors propagate in the public domain, while editing or morphing occur, particularly through social media. The mathematical-computational models of epidemics are currently well known, which can be used to predict or back-predict the spread of infections accurately. One such phylodynamic study that combined a modeling framework for host, epidemiological and molecular data, particularly for RNA viruses, such as SARS-CoV-2 demonstrated particular promise for understanding the patterns of viral evolution during 

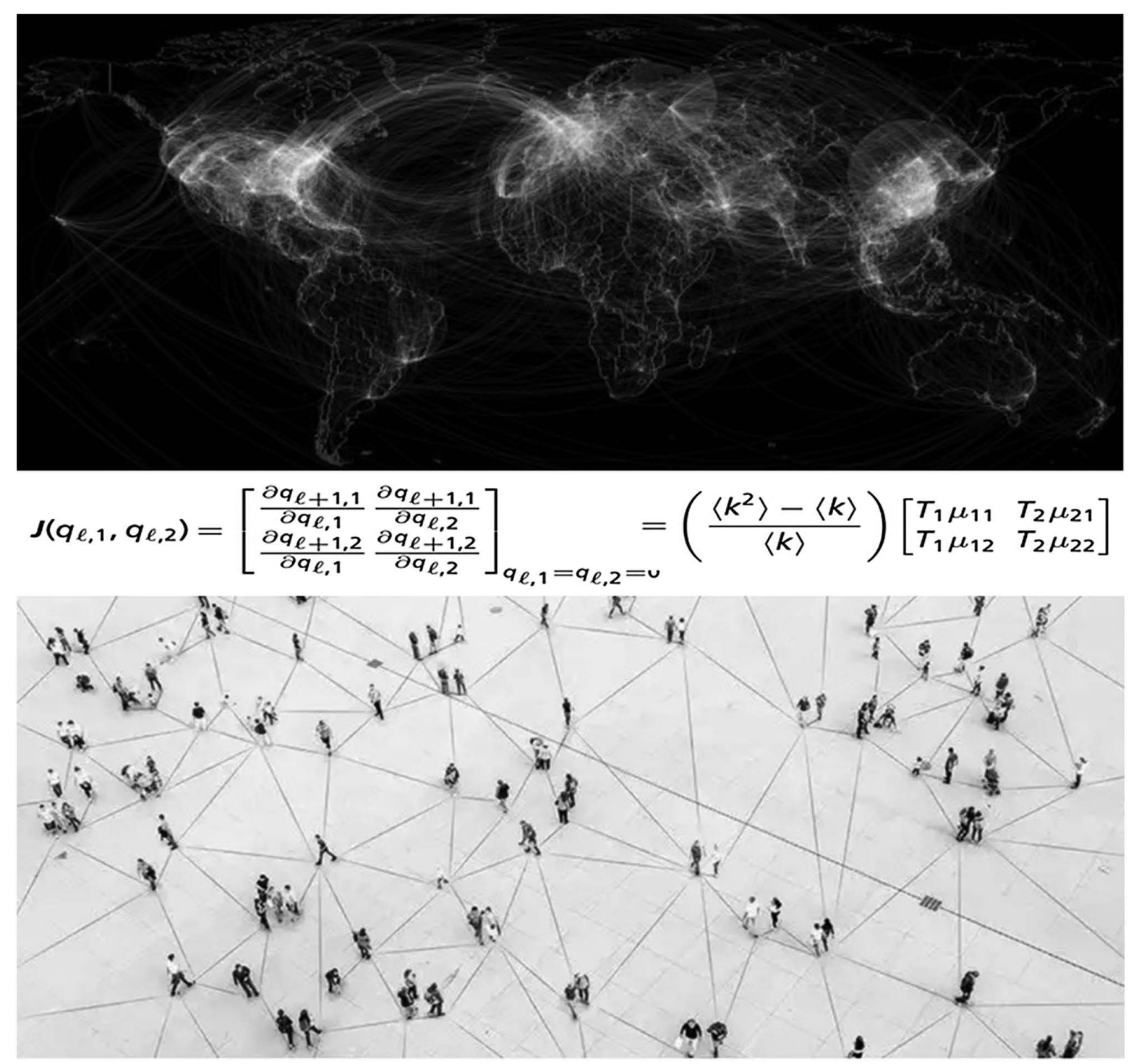

Figure 6. A symbolic representation of mathematical modelling of pandemics similar to COVID-19.

epidemics or pandemics (3). An example of this is the first case-clusters of the SARS-CoV-1 outbreak and the subsequent global spread, including the country-by-country distribution of human cases $(66,67)$. Notably, the phylodynamic analysis estimated the median time to most recent common ancestor (TMRCA) as November 17, 2019 and a genetic mutation rate of $0.8 \times 10^{-3}$ (95\% CI, $0.14 \times 10^{-3}$ to $1.31 \times 10^{-3}$ ) (46). In addition, that study predicted the doubling time of viral infections each week (7.2 days). However, it is essential to note that mutation rates differ from viral protein-to-protein and study-to-study due to the rapid increase in sequencing data. A recently proposed mathematical theory highlighted the emergence phenomena of COVID-19 or similar infections and revealed the effects of evolutionary adaptations on spreading processes in complex networks (Fig. 6), overcoming the flaws of classical epidemic models that do not capture evolution (68). This model fully characterizes the process, accurately predicts the epidemics threshold, the expected epidemic size, and the expected fraction of individuals infected by each pathogenic strain. Moreover, another recent algorithm based on a bacterial protein model could also help understand the evolutionary pathway of
SARS-CoV-2 that evades the immune system or those viruses who develop drug-resistance in due course of time (69).

\section{Risk factors}

It is now well known that emerging human viruses can be transmitted to humans via close contact with virus-hosting animals and the consumption of infected meat or meat products, including freshwater and seafood products (2). The new approach to food safety and protecting humans against food-borne infections is the most effective method with which to control human illnesses associated with zoonosis. However, the vast majority of such infections remain under-reported, and therefore, novel viral pathogens remain unidentified and continue to circulate in the general population. As zoonosis is linked to the majority of the pathogenic viruses, including SARS-CoV-1 and SARS-CoV-2, precautions and proper care are required, while selecting, purchasing, cooking, consuming meat or seafood and avoiding high-risk animals is also mandatory. Globally, the current bio-/food-security measures appear to be more successful in constraining bacterial and fungal 
pathogens that have been less effective for water-/food-borne viruses (2).

Recent clinical reports on gastrointestinal and stool shedding of SARS-CoV-2 suggest potential routes of transmission of COVID-19. Therefore, occurrences of SARS-CoV-2 in human feces and water sources under poor sanitation conditions may further aggravate the fecal-oral spread of COVID-19 in healthcare-deficient nations (70). Nonetheless, further studies are warranted in order to determine whether infectious and transmittable amounts of SARS-CoV-2 can be found in water sources. Moreover, the surveillance of emerging human viruses, such as SARS-CoV-2 must, therefore, include livestock, wild animals, potential vectors and their environments at an internationally coordinated level. Furthermore, animal handlers, such as livestock herders, hunters, sellers, forest rangers, zookeepers, wildlife rangers and veterinarians working with potential reservoir or high-risk animals must take hygienic measures, as well as undergo routine serological tests.

\section{Conclusion and future perspectives}

The majority of novel human-adapted viruses with known origin fall into the category of 'crowd diseases' that require relatively high host-densities for rapid spread and are greatly enhanced by air travel. Notably, recent incidences of COVID-19, such as pandemics mark the Asia-Pacific region as the global hot-spot for emerging novel pathogenic viruses. There is a growing understanding of COVID-19 pathobiology, epidemiology and clinical management strategies. However, as evidenced by recent clinical studies, asymptomatic, as well as discharged patients, can still remain viremic. The presence of SARS-CoV-2 RNA in uncommon areas of infection, such as the rectum, despite the absence of viral load in swabs from regularly affected areas, highlights the shortcomings in screening, diagnosis and understanding the spread. The viral shedding in such specimens thereby provides a cautionary warning that COVID-19 may be transmitted through the fecal-oral route in developing countries with inadequate sanitization. Most importantly, the detection of SARS-CoV-2 in rectal and fecal samples strongly endorses its digestive etiology, directly or indirectly, in higher-risk patients with impaired immunity.

Worldwide, government authorities, healthcare providers and non-profit organizations are enforcing safety guidelines, and providing diagnostics and treatments to the best of their capacities. Unfortunately, by the time an effective COVID-19 vaccine is available or the tempting 'herd immunity' scenario is expedited, millions of lives could be lost, and there would be deleterious effects on the health system and economy worldwide. However, the mass production and open-sharing of sensitive and cost-effective test kits may be a rapid tool with which to identify infected and asymptomatic carriers and save the healthy population. Moreover, epidemiologists and statisticians can adopt the recently introduced mathematical models to predict further and estimate the future COVID-19 spread and control measures. Nonetheless, the real impact of COVID-19 will be known only after the pandemic is over.

This is the time when international collaborations and co-ordinations are most needed towards the better utilization of available resources. Nonetheless, few key issues must be addressed sincerely, as for instance, ensuring that the preset standard protocols are appropriately followed amid the rush of assessing and approving new COVID-19 drugs, as recently experienced with the hydroxychloroquine controversy. The care of other infectious or chronic diseases should not be compromised, resulting in a significant increase in mortality. The mental health of patients with COVID-19 and their families, healthcare providers, local administrative or security officials, and underprivileged individuals must be appropriately taken into consideration in order to prevent long-term psychological disorders. Moreover, lastly but importantly, the UNO and WHO must manage the existing distrust and isolated actions among politically distanced countries to prevent any future escalation in the crisis. In addition, it becomes the civic responsibility of academics and scientists to proactively reach out to the common man to educate on the current understanding of disease via social media. Therefore, the biomedical, socio-economical and geopolitical forces of the world must work together to end the COVID-19 emergency soon. On a positive note, treated patients are recovering, and the virus is being contained. The future is not dismal. Importantly, with a united effort, the indomitable spirit of humanity can remain undefeated.

\section{Acknowledgements}

MKP gratefully acknowledges his virology mentors, Dr Shahid Jameel (CEO, Welcome-Trust India Alliance, Hyderabad, India); Dr Syed S. Hasnain (VC, Hamdard University, New Delhi, India); Dr Shiv K. Sarin (Director, Institute of Liver and Biliary Sciences, New Delhi, India); Dr Robert H. Purcell and Dr Suzanne U. Emerson (Chief Scientists, National Institutes of Health, Bethesda, USA); and Dr Robert C. Gallo (Director, Institute of Human Virology, Baltimore, USA) for providing education and inspiration in the field.

\section{Funding}

No funding received.

\section{Availability of data and materials}

Not applicable.

\section{Authors' contributions}

MKP conceptualized, planned and designed the study, performed the literature search, and drafted, edited and prepared the final version of the manuscript. RMJ, RSP, SKSV, VA, JK and NT conceptualized and participated in the design, literature search, and writing and drafting of the manuscript. All authors have read and approved the final manuscript.

\section{Ethics approval and consent to participate}

Not applicable.

\section{Patient consent for publication}

Not applicable. 


\section{Competing interests}

The authors declare that they have no competing interests.

\section{References}

1. World Health Organization (WHO): Coronavirus disease (COVID-19) outbreak situation. https://www.who.int/emergencies/diseases/novel-coronavirus-2019. Accessed June 20, 2020.

2. Parvez MK: Emerging and re-emerging viral diseases: Controls and preventions. In: Microbial pathogens and strategies for combating them science, technology and education Méndez-Vilas A (ed). Formatex Research Center, Badajoz, 2013.

3. Parvez MK and Parveen S: Evolution and emergence of pathogenic viruses: Past, present, and future. Intervirology 60: 1-7, 2017.

4. Wever PC and van Bergen L: Death from 1918 pandemic influenza during the first world war: A perspective from personal and anecdotal evidence. Influenza Other Respir Viruses 8: 538-546, 2014.

5. International Committee on Taxonomy of Viruses (ICTV): Virus taxonomy: The classification and nomenclature of viruses. https://talk.ictvonline.org/ictv-reports/ictv_online_report/. Accessed June 20, 2020.

6. Ren LL, Wang YM, Wu ZQ, Xiang ZC, Guo L, Xu T, Jiang YZ, Xiong Y, Li YJ, Li XW, et al: Identification of a novel coronavirus causing severe pneumonia in human: A descriptive study. Chin Med J (Engl) 133: 1015-1024, 2020.

7. World Health Organization (WHO): Director-General's opening remarks at the media briefing on COVID-19. https://www.who. $\mathrm{int} / \mathrm{dg} /$ speeches/detail/who-director-general-s-opening-remarks-atthe-media-briefing-on-covid-19-18-march-2020. Accessed June 20,2020.

8. Huang C, Wang Y, Li X, Ren L, Zhao J, Hu Y, Zhang L, Fan G, Xu J, Gu X, et al: Clinical features of patients infected with 2019 novel coronavirus in Wuhan, China. Lancet 395: 497-506, 2020.

9. Kissler SM, Tedijanto C, Goldstein E, Grad YH and Lipsitch M Projecting the transmission dynamics of SARS-CoV-2 through the postpandemic period. Science 368: 860-868, 2020.

10. Bauch CT and Oraby T: Assessing the pandemic potential of MERS-CoV. Lancet 382: 662-664, 2013.

11. Chen Y, Liu Q and Guo D: Emerging coronaviruses: Genome structure, replication, and pathogenesis. J Med Virol 92: 418-423, 2020.

12. Chen B, Liang H, Yuan X, Hu Y, Xu M, Zhao Y, Zhang B, Tian F and Zhu X: Roles of meteorological conditions in COVID-19 transmission on a worldwide scale. medRxiv: https://doi.org/10.1 101/2020.03.16.20037168

13. Cárdenas-Conejo Y, Liñan-Rico A, García-Rodríguez DA Centeno-Leija S and Serrano-Posada H: An exclusive 42 amino acid signature in pplab protein provides insights into the evolutive history of the 2019 novel human-pathogenic coronavirus (SARS-CoV-2). J Med Virol 92: 688-692, 2020.

14. Wu F, Zhao S, Yu B, Chen YM, Wang W, Song ZG, Hu Y, Tao ZW, Tian JH, Pei YY, et al: A new coronavirus associated with human respiratory disease in China. Nature 579: 265-269, 2020.

15. Coronaviridae Study Group of the International Committee on Taxonomy of Viruses: The species severe acute respiratory syndrome-related coronavirus: Classifying 2019-nCoV and naming it SARS-CoV-2. Nat Microbiol 5: 536-544, 2020.

16. Kumar S, Maurya VK, Prasad AK, Bhatt MLB and Saxena SK Structural, glycosylation and antigenic variation between 2019 novel coronavirus (2019-nCoV) and SARS coronavirus (SARS-CoV). Virus Disease 31: 13-21, 2020.

17. Chan JF, Kok KH, Zhu Z, Chu H, Kai-Wang K, Yuan S and Yuen KY: Genomic characterization of the 2019 nove human-pathogenic coronavirus isolated from a patient with atypical pneumonia after visiting Wuhan. Emerg Microbes Infect 9: 221-236, 2020

18. Walls AC, Park YJ, Tortorici MA, Wall A, McGuire AT and Veesler D: Structure, function, and antigenicity of the SARS-CoV-2 spike glycoprotein. Cell 181: 281-292.e286, 2020.

19. Coutard B, Valle C, de Lamballerie X, Canard B, Seidah NG and Decroly E: The spike glycoprotein of the new coronavirus 2019-nCoV contains a furin-like cleavage site absent in $\mathrm{CoV}$ of the same clade. Antiviral Res 176: 104742, 2020

20. Wan Y, Shang J, Graham R, Baric RS and Li F: Receptor recognition by the novel coronavirus from Wuhan: An analysis based on decade-long structural studies of SARS coronavirus. J Virol 94: e00127-e00120. 2020
21. Wrapp D, Wang N, Corbett KS, Goldsmith JA, Hsieh CL, Abiona O, Graham BS and McLellan JS: Cryo-EM structure of the 2019-nCoV spike in the prefusion conformation. Science 367 $1260-1263,2020$

22. Leung DT, Tam FC, Ma CH, Chan PK, Cheung JL, Niu H, Tam JS and Lim PL: Antibody response of patients with severe acute respiratory syndrome (SARS) targets the viral nucleocapsid. J Infect Dis 190: 379-386, 2004.

23. European Center for Disease Prevention and Control (ECDC): COVID-19 situation update worldwide, as of 6 July 2020 https://www.ecdc. europa.eu/en/geographical-distribution-2019ncov-cases. Accessed June 20, 2020.

24. Schoeman D and Fielding BC: Coronavirus envelope protein Current knowledge. Virol J 16: 69, 2019.

25. Kakodkar P, Kaka N and Baig MN: A comprehensive literature review on the clinical presentation, and management of the pandemic coronavirus disease 2019 (COVID-19). Cureus 12: e7560, 2020.

26. Li Y and Xia L: Coronavirus disease 2019 (COVID-19): Role of chest CT in diagnosis and management. AJR Am J Roentgenol 214: 1280-1286, 2020.

27. Wong HYF, Lam HYS, Fong AH, Leung ST, Chin TW, Lo CS Lui MM, Lee JC, Chiu KW, Chung T, et al: Frequency and distribution of chest radiographic findings in COVID-19 positive patients. Radiology 2011: 60, 2019 (Online ahead of print).

28. Ge XY, Li JL, Yang XL, Chmura AA, Zhu G, Epstein JH, Mazet JK, Hu B, Zhang W, Peng C, et al: Isolation and characterization of a bat SARS-like coronavirus that uses the ACE2 receptor. Nature 503: 535-538, 2013.

29. Li W, Moore MJ, Vasilieva N, Sui J, Wong SK, Berne MA, Somasundaran M, Sullivan JL, Luzuriaga K, Greenough TC, et al: Angiotensin-converting enzyme 2 is a functional receptor for the SARS coronavirus. Nature 426: 450-454, 2003.

30. Hamming I, Timens W, Bulthuis ML, Lely AT, Navis G and van Goor H: Tissue distribution of ACE2 protein, the functional receptor for SARS coronavirus. A first step in understanding SARS pathogenesis. J Pathol 203: 631-637, 2004.

31. Fang L, Karakiulakis G and Roth M: Are patients with hypertension and diabetes mellitus at increased risk for COVID-19 infection? Lancet Respir Med 8: e21, 2020.

32. Totura AL and Baric RS: SARS coronavirus pathogenesis: Host innate immune responses and viral antagonism of interferon. Curr Opin Virol 2: 264-275, 2012.

33. Adams DH and Hubscher SG: Systemic viral infections and collateral damage in the liver. Am J Pathol 168: 1057-1059, 2006.

34. Gu J, Han B and Wang J: COVID-19: Gastrointestinal manifestations and potential fecal-oral transmission. Gastroenterology 158 $1518-1519,2020$

35. Zhang C, Shi L and Wang FS: Liver injury in COVID-19: Management and challenges. Lancet Gastroenterol Hepatol 5 : 428-430, 2020

36. Wang D, Hu B, Hu C, Zhu F, Liu X, Zhang J, Wang B Xiang H, Cheng Z, Xiong Y, et al: Clinical characteristics of 138 hospitalized patients with 2019 novel coronavirus-infected pneumonia in Wuhan, China. JAMA 323: 1061-1069, 2020.

37. Guan WJ, Ni ZY, Hu Y, Liang WH, Ou CQ, He JX, Liu L, Shan H, Lei CL, Hui DSC, et al: Clinical characteristics of coronavirus disease 2019 in China. N Engl J Med 382: 1708-1720, 2020.

38. Shi H, Han X, Jiang N, Cao Y, Alwalid O, Gu J, Fan Y and Zheng C: Radiological findings from 81 patients with COVID-19 pneumonia in Wuhan, China: A descriptive study. Lancet Infect Dis 20: 425-434, 2020.

39. Qi F, Qian S, Zhang S and Zhang Z: Single cell RNA sequencing of 13 human tissues identify cell types and receptors of human coronaviruses. Biochem Biophys Res Commun 526: 135-140, 2020.

40. Li B, Yang J, Zhao F, Zhi L, Wang X, Liu L, Bi Z and Zhao Y: Prevalence and impact of cardiovascular metabolic diseases on COVID-19 in China. Clin Res Cardiol 109: 531-538, 2020.

41. Long B, Brady WJ, Koyfman A and Gottlieb M: Cardiovascular complications in COVID-19. Am J Emerg Med 38: 1504-1507, 2020

42. Lippi $\mathrm{G}$ and Plebani M: Laboratory abnormalities in patients with COVID-2019 infection. Clin Chem Lab Med 58: 1131-1134, 2020.

43. Li JW, Han TW, Woodward M, Anderson CS, Zhou H, Chen YD and Neal B: The impact of 2019 novel coronavirus on heart injury: A systemic review and meta-analysis. Prog Cardiovasc Dis: April 16, 2020 (Epub ahead of print) 
44. Guan Y, Zheng BJ, He YQ, Liu XL, Zhuang ZX, Cheung CL, Luo SW, Li PH, Zhang LJ, Guan YL, et al: Isolation and characterization of viruses related to the SARS coronavirus from animals in southern China. Science 302: 276-278, 2003.

45. Li W, Shi Z, Yu M, Ren W, Smith C, Epstein JH, Wang H, Crameri G, Hu Z, Zhang $\mathrm{H}$, et al: Bats are natural reservoirs of SARS-like coronaviruses. Science 310: 676-679, 2005.

46. Andersen KG, Rambaut A, Lipkin WI, Holmes EC and Garry RF: The proximal origin of SARS-CoV-2. Nat Med 26: 450-452, 2020

47. Corman VM, Eckerle I, Bleicker T, Zaki A, Landt O, Eschbach-Bludau M, van Boheemen S, Gopal R, Ballhause M, Bestebroer TM, et al: Detection of a novel human coronavirus by real-time reverse-transcription polymerase chain reaction. Euro Surveill 17: 20285, 2012.

48. Banerjee A, Kulcsar K, Misra V, Frieman M and Mossman K: Bats and Coronaviruses. Viruses 11: 41, 2019.

49. Reusken CB, Raj VS, Koopmans MP and Haagmans BL: Cross host transmission in the emergence of MERS coronavirus. Curr Opin Virol 16: 55-62, 2016.

50. Laguipo A: Tiger with SARS-CoV-2 infection demostrates reverse zoonosis. News-Medical, 2020. https://www.news-medical net/news/20200406/Tiger-with-SARS-CoV-2-infection-demostrates -reverse-zoonosis.aspx. Accessed April 6, 2020

51. Zhang W, Du RH, Li B, Zheng XS, Yang XL, Hu B, Wang YY, Xiao GF, Yan B, Shi ZL and Zhou P: Molecular and serological investigation of 2019-nCoV infected patients: Implication of multiple shedding routes. Emerg Microbes Infect 9: 386-389, 2020.

52. Xu Y, Li X, Zhu B, Liang H, Fang C, Gong Y, Guo Q, Sun X, Zhao D, Shen J, et al: Characteristics of pediatric SARS-CoV-2 infection and potential evidence for persistent fecal viral shedding. Nat Med 26: 502-505, 2020.

53. Holshue ML, DeBolt C, Lindquist S, Lofy KH, Wiesman J, Bruce H, Spitters C, Ericson K, Wilkerson S, Tural A, et al: First case of 2019 novel coronavirus in the United States. N Engl J Med 382: 929-936, 2020

54. Tang A, Tong ZD, Wang HL, Dai YX, Li KF, Liu JN, Wu WJ, Yuan C, Yu ML, Li P and Yan JB: Detection of novel coronavirus by RT-PCR in stool specimen from asymptomatic child, China. Emerg Infect Dis 26: 1337-1339, 2020.

55. Young BE, Ong SWX, Kalimuddin S, Low JG, Tan SY, Loh J, Ng OT, Marimuthu K, Ang LW, Mak TM, et al: Epidemiologic features and clinical course of patients infected with SARS-CoV-2 in Singapore. JAMA 323: 1488-1494, 2020.

56. van Doremalen N, Bushmaker T, Morris DH, Holbrook MG, Gamble A, Williamson BN, Tamin A, Harcourt JL, Thornburg NJ, Gerber SI, et al: Aerosol and surface stability of SARS-CoV-2 as compared with SARS-CoV-1. N Engl J Med 382: 1564-1567, 2020.

57. Jin YH, Cai L, Cheng ZS, Cheng H, Deng T, Fan YP, Fang C, Huang $\mathrm{D}$, Huang LQ, Huang Q, et al: A rapid advice guideline for the diagnosis and treatment of 2019 novel coronavirus (2019-nCoV) infected pneumonia (standard version). Mil Med Res 7: 4, 2020.
58. Borba MGS, Val FFA, Sampaio VS, Alexandre MAA, Melo GC, Brito M, Mourão MPG, Brito-Sousa JD, Baía-da-Silva D, Guerra MVF, et al: Chloroquine diphosphate in two different dosages as adjunctive therapy of hospitalized patients with severe respiratory syndrome in the context of coronavirus (SARS-CoV-2) infection: Preliminary safety results of a randomized, double-blinded, phase IIb clinical trial (CloroCovid-19 Study). medRxiv: doi: https://doi.org/10.1101/2020.04.07.20056424.

59. Chorin E, Dai M, Shulman E, Wadhwani L, RoiBar-Cohen, Barbhaiya C, Aizer A, Holmes D, Bernstein S, Spinelli M, et al: The QT interval in patients with SARS-CoV-2 infection treated with hydroxychloroquine/azithromycin. medRxiv: doi: https://doi.org/10.1101/2020.04.02.20047050.

60. Roden DM, Harrington RA, Poppas A and Russo AM: Considerations for drug interactions on QTc in exploratory COVID-19 (coronavirus disease 2019) treatment. Heart Rhythm 17: e231-e232, 2020.

61. Huang J, Song W, Huang H and Sun Q: Pharmacological therapeutics targeting RNA-dependent RNA polymerase, proteinase and spike protein: From mechanistic studies to clinical trials for COVID-19. J Clin Med 9: 1131, 2020.

62. Center for Disease control (CDC): Information for Clinicians on Investigational Therapeutics for Patients with COVID-19.https://www.cdc.gov/coronavirus/2019-ncov/hcp/therapeutic-options.html. Accessed April 25, 2020.

63. Akst J: COVID-19 Vaccine Frontrunners. The scientist, 2020. https://www.the-scientist.com/news-opinion/covid-19-vaccinefrontrunners-67382. Accessed June 20, 2020.

64. Zhang C, Chen C, Shen W, Tang F, Lei H, Xie Y, Cao Z, Tang K, Bai J, Xiao L, et al: Impact of population movement on the spread of 2019-nCoV in China. Emerg Microbes Infect 9: 988-990, 2020.

65. Chinazzi M, Davis JT, Ajelli M, Gioannini C, Litvinova M, Merler S, Piontti APY, Mu K, Rossi L, Sun K, et al: The effect of travel restrictions on the spread of the 2019 novel coronavirus (COVID-19) outbreak. Science 368: 395-400, 2020.

66. Anderson RM, Fraser C, Ghani AC, Donnelly CA, Riley S, Ferguson NM, Leung GM, Lam TH and Hedley AJ: Epidemiology, transmission dynamics and control of SARS: The 2002-2003 epidemic. Philos Trans R Soc Lond B Biol Sci 359: 1091-1105, 2004

67. Hufnagel L, Brockmann D and Geisel T: Forecast and control of epidemics in a globalized world. Proc Natl Acad Sci USA 101: 15124-15129, 2004.

68. Eletreby R, Zhuang Y, Carley KM, Yagan O and Poor HV: The effects of evolutionary adaptations on spreading processes in complex networks. Proc Natl Acad Sci USA 117: 5664-5670, 2020.

69. Zhou J and McCandlish DM: Minimum epistasis interpolation for sequence-function relationships. Nat Commun 11: 1782, 2020.

70. Parvez MK: Gastrointestinal and hepatobiliary manifestations of coronavirus disease-19: Potential implications for healthcare resource-deficient countries. Gastroenterol Heptal Lett 2: 7-11, 2020.

This work is licensed under a Creative Commons Attribution-NonCommercial-NoDerivatives 4.0 International (CC BY-NC-ND 4.0) License. 